
\title{
is Research Soure \\ Are General Practices Adequately Funded to Serve High Proportions of High Need Patients?
}

\author{
Tessa Senior ( $\nabla$ tessa.senior@vuw.ac.nz ) \\ Victoria University of Wellington \\ Mona Jeffreys \\ Victoria University of Wellington \\ Jacqueline Cumming \\ Victoria University of Wellington \\ Peter Crampton \\ University of Otago \\ Maite Irurzun Lopez \\ Victoria University of Wellington \\ Kenny Hau \\ University of Otago
}

\section{Research Article}

Keywords: equity, Māori health, capitation, primary care funding, formula, general practise, modelling.

Posted Date: January 24th, 2022

DOI: https://doi.org/10.21203/rs.3.rs-1255353/v1

License: (c) (i) This work is licensed under a Creative Commons Attribution 4.0 International License. Read Full License 


\section{Abstract}

Background: Capitation formulas take into account the characteristics of the population served as a way of estimating the funding required to meet varying levels of need. Capitation is a well-established method of funding health care in many different counties, especially in primary care. In Aotearoa New Zealand (ANZ), a capitation formula has been used since 2002 to fund all general practices. However, general practices who service greater numbers of people with complex health needs may not be funded adequately using the current formula if the characteristics used in the formula do not appropriately reflect the varying needs of those enrolled. We sought to quantify the levels of funding received by general practices who serve high proportions of high needs people, in order to assess if general practices are adequately funded to do so.

Method: Ministry of Health enrolment data was used to inform the demographic spread of five hypothetical 5,000 patient practices consisting of: $30 \%, 50 \%, 70 \%, 90 \%$ and $100 \%$ high needs people. High needs were defined as those who fit one or more of these three criteria: Māori ethnicity; Pacific ethnicity; and people residing in an area of high socioeconomic deprivation. Annual first level services payments, High User Health Card, and additional funding streams including Very Low-Cost Access, Community Service Cards (CSC) and Fees-free for under 14s were taken from the Primary Health Organisation Services Agreement contract to calculate levels of income for all hypothetical practices.

Results: Age is a strong determinant of capitation funding. Practice level funding does not increase in proportion to the level of needs of the populations served. VLCA funding is higher for the $70 \%$ high need then the $90 \%$ high need practice. CSC and Fees-free under 14s funding increase as the percentage of high needs people increase but not proportionally to the level of need.

Conclusion: Use of age and sex as the main determinants for capitation funding shows evidence of structural discrimination within the health system. Funding schemes aimed at helping high needs populations do not always result in adequate funding for general practices to serve these communities well.

\section{Introduction}

Capitation formulas are used in many OECD countries, including the United Kingdom (UK), Italy, Australia, Canada and Aotearoa New Zealand to fund primary and/or secondary health care services ${ }^{1}$. A capitation funding formula takes into account the size and characteristics of the population served, as a way of estimating the funding required to meet their health needs ${ }^{2}$. A meta-analysis of seven countries found that demographic-based formulas in primary care are largely modelled on historic general practice utilisation. The authors concluded that these formulas do not always account for the issues some populations face in accessing care and often serve to reinforce existing health disparities

Primary care services in Aotearoa New Zealand are mainly funded through capitation-based payments to general practices, supplemented by a user co-payment. The introduction of capitation was part of a radical reform in 2001 called the Primary Health Care Strategy (PHCS) ${ }^{4}$. Through the PHCS, 'first level service' (i.e., GP consultations, diagnosis and health promotion) capitation payments are provided to practices on the basis of the age and sex of people enrolled, as determined by the Primary Health Organisation Service Agreement Amendment Protocol (PSAAP) ${ }^{5}$. The capitation formula was created based on 1998/99 average general practitioner (GP) utilisation rates. These payments were not weighted for ethnicity and deprivation because at the time of creation, there existed limited data. The data that did exist showed similar utilisation rates for all groups, in spite of the knowledge that Māori, Pacific peoples and those living in deprivation are more likely to have poorer health and greater barriers to accessing care ${ }^{6}$. 
These payments account for $80 \%$ of total PHO funding ${ }^{7}$. Higher levels of capitation funding are provided according to whether someone has a High Use Health Card (HUHC) or not. To be eligible for a HUHC, a patient must have visited a practice 12 or more times in one year, for specific ongoing condition(s); GPs must also apply for such cards for their patients.

The government later introduced a new collection of funds called the Flexible Funding Pool (FFP) which included, Services to Improve Access (SIA) and Health Promotion (HP). Both SIA and HP funds were weighted for ethnicity and deprivation. However, these pools represented only a small proportion of primary care, and both pools of funding were provided for the new Primary Health Organisations ${ }^{8}$ - meso-level organisations contracted by the government to work with and support general practices - rather than to the general practices themselves. Despite this effort to acknowledge the greater health needs of certain population groups, the FFP only accounts for $16 \%$ of overall PHO funding ${ }^{7}$.

In order to combat barriers to access for key population groups, various additional policies have been developed over time. Between 2006 and 2009, Very Low Cost Access (VLCA) practice funding was introduced ${ }^{9}$. These practices must serve at least $50 \%$ "high needs" patients: high needs being defined as those who fit one or more of these three criteria: being Māori or Pacific ethnicity or living in an area that is classified as NZDep quintile 5. The NZDep is an area-based measure of socioeconomic deprivation; deprivation scores are ranked and split into quintiles, with 1 being the lowest level of deprivation and 5 being the highest ${ }^{10}$. VLCA practices receive a higher amount of funding but are required to cap user co-payments (At the time of writing, this cap is set at $\$ 19.50$ for adults $18+$ ).

In 2018, additional funding was provided to allow similar benefits for holders of Community Service Cards (CSCs), an initiative aimed at reducing the cost of health care for low income families. Non-VLCA practices receiving such funding must also agree to cap user co-payments (to the same level as VLCA practices).

Each of these policies where designed to provide more equitable funding for practices and to reduce key barriers to accessing care for key population groups ${ }^{11}$. Yet in spite of such policies, Aotearoa New Zealand's funding formula has continued to be criticised for failing to recognise differing health needs by ethnicity and consideration of case complexity ${ }^{12,13}$. The current formula also does not recognise the earlier age onset of often multiple long-term diseases such as diabetes and cardiovascular in Māori compared to non-Māori ${ }^{14}$.

Despite the PHCS objective to reduce health inequities between different population groups, primary care funding has not been sufficiently redressed to achieve this goal. We have recently demonstrated that high needs populations have higher levels of morbidity, multimorbidity and general practice utilisation than non-high needs populations . Compared to non-high-need people, high need respondents were more likely to report three or more chronic conditions (15\% vs $12 \%)$, and high needs people were also more likely to visit a general practise more often in the 'seven or more times' category than non-high-need people (8.7\% vs $6.6 \%)$. The aim of this research is to determine whether the current formula accounts for this increased financial burden and contribute to the assessment of whether there is evidence of structural discrimination within the health sector based on capitation formula.

\section{Methods}

Our work was based on five hypothetical practices, each with an enrolment of 5,000 patients, but differing according to density of high need patients; 1) $30 \%$ high needs, $70 \%$ non-high needs, 2) 50\% each of high and non-high needs, 3) $70 \%$ high needs, 30\% non-high needs, 4) $90 \%$ high needs, 10\% non-high needs, and 5) a side-by-side comparison of a $100 \%$ high needs practice next to a $100 \%$ non-high needs practice. We assumed that the high needs populations in 
each of our hypothetical practices had an age distribution of the Māori population, and that the non- high needs population had an age distribution of the non-Māori population. Using the general population to model our practices would mean that age would confound our results as we know high needs groups have a different age distribution, i.e. they are typically younger ${ }^{16}$. Age categories were those defined by the Ministry of Health funding formula; $0-4,5-14$, $15-24,25-44,45-64$ and $65+$.

Aggregated Ministry of Health Primary Health Organisation enrolment data is publicly available. These data are collected from the patient at the point of enrolment with a GP, which in turn is provided to the PHO with which the practice has an association with. The data consists of personal demographic variables and PHO details. This information, from June 2021, was used to determine the age and sex distribution and the need status (high need/nonhigh need) of our population which informed our five hypothetical practices. The enrolment data also provided us with a breakdown of people with and without a CSC and HUHC.

The PHO Services Agreement is a contract between PHOs and the Government. It outlines rates and funding criteria. This agreement is updated every year; we used the most up to date edition available at the time of conducting our research ${ }^{5}$, dated June 2021. This document includes funding figures which we used to inform our models for capitation funding, VLCA, CSC and HUHC. All funding figures are annual.

\section{First-level services capitation}

There are two types of first-level services capitation funding, one for Access practices and one for non-Access practices. The categories are historical, being put in place in the early years of the PHCS, to enable new funding for primary care to be rolled out first to Access practices and then, by age groups, to non-Access practices. Since the completion of the roll out in 2007, there now exists little difference between the funding amount of these two practice types. There is a very slightly higher level of funding for younger people, who do not have a HUHC, in an Access practice but not enough to make a meaningful difference in overall funding. We chose to use figures for the Access practices because these practices were originally intended to serve a high needs population.

\section{High user health cards}

These cards are applied for by the practice, on behalf of the patient. They are allocated to patients who consult a GP 12 or more times a year. Funding for HUHC is part of the capitation payment; we present the HUHC payments separately for transparency. For example, capitation rates for someone with a HUHC, for a female age 0-4, are NZ\$682.27; rates for someone without a HUHC are NZ\$456.42; the difference (NZ\$225.85) is the HUHC payment that we used in our calculations.

\section{VLCA practices}

To be a VLCA practice, $50 \%$ or more of the enrolled population must be high needs.

These practices also agree to keep patient co-payment fees capped (currently at NZ\$19.50 for adults) in return for receiving an additional payment on top of the capitation funding, for each enrolled person in the practice, including an extra payment for CSC holders.

\section{Community Services Card holders}

CSCs are available to those households with a low household income, in public housing, or receiving an accommodation supplement. This includes many people including older people on government superannuation, 
students, veterans, or people over 16 and living away from home. Since 2018, practices have been entitled to a higher rate of capitation funding for each enrolled person who holds a CSC, provided that the practice has joined the scheme and agreed for co-payments to be capped (to the same level for VLCA practices).

\section{Statistical methods}

To obtain an accurate demographic structure of our population, we used Ministry of Health enrolment data (June, $2021)^{17}$. We did this by taking general population totals and calculating what percentage of the population made up each demographic group. For example, our population contains 43,360 high need males aged 0-4, which equals 5.3\% of the high needs population. These proportions were then applied to our hypothetical 5,000-person practice, e.g., $5.3 \%$ of our 5,000-person practice with $50 \%$ high needs patients would be 133 people. This gave us our total number of enrolled patients, in each practice, by age, needs status and sex. These proportions were then used to build our hypothetical practices and to calculate their capitation funding totals.

Current funding formulas from the PHO agreement ${ }^{5}$ were used to inform our models for capitation and VLCA funding. For example, we have 133 patients in our 0-4 years, high needs male group in our 50\% practice. This age group is funded NZ\$480.55 in capitation payments, per patient; therefore, funding for this group would come to NZ\$63,913.15 per year (480.55 x \$133). This approach was then repeated for each age/sex category in each of the five hypothetical practices. We repeated this distribution formula for the VLCA payments. We did not include the $30 \%$ high needs practice in these calculations as they would not qualify for VLCA payments based on the criteria of needing $50 \%$ high needs enrolees to qualify.

Unlike capitation and VLCA payments which are applied to every person in our hypothetical practice, CSC and HUHC are different as not all patients qualify for this payment. Our method for calculating these payments was slightly different because we had to include the proportion of people who do and do not have one of the cards. The enrolment data provided us with these totals; we then used the same calculations as with the capitation funding to find the proportion of our hypothetical practise who would and would not have the cards.

\section{Results}

Figure 1 shows two hypothetical practices, one with 100\% high needs enrolment and one with 100\% not high needs enrolment. This shows that age is a strong determinant of capitation funding. The funding levels in part reflect the different age distributions of the populations - with Māori and Pacific populations having a younger age profile, and non-Māori, non-Pacific having an older age profile; this interacts with the funding formula which provides significant funder for older people (65+).

Figure 2 shows the first level service capitation funding of all four of our hypothetical practices. This shows that the first level services rates are similar for all our practices and there is not a proportionate increase in funding for practices that cater for a higher proportion of high needs people.

Figure 3 shows the VLCA funding that each hypothetical practice receives[JC4] [TS5] [TS6] . This does not include first level capitation funding, just the isolated VLCA payments. The $90 \%$ hypothetical high needs practice has a lower amount of funding than the $70 \%$ practice. This is due to the age distribution; the high needs population has a lower proportion of older people due to lower median age of Māori and Pacific people.

Table 1 shows the overall income, from the streams we have modeled, for a non-VLCA practice. Both CSC and feesfree Under 14 s funding increase in a sequential way, although not proportionally to the increase in high needs patients. 
HUHC has minimal impact in relation to other funding sources, HUHC funding does not increase proportionately as our $90 \%$ high need practice receives a lesser revenue than the $70 \%$ practice.

Table 1: Annual practice income from all funding streams for hypothetical non-VLCA practices. (Figures in NZ\$\$)

\begin{tabular}{|llllll|}
\hline & $\begin{array}{l}\text { First level service } \\
\text { Capitation }\end{array}$ & $\begin{array}{l}\text { Fees-free under } \\
\mathbf{1 4 s}\end{array}$ & CSC & HUHC & Totals \\
\hline $\begin{array}{l}\text { Proportion of high needs } \\
\text { patients }\end{array}$ & & & & & \\
\hline $\mathbf{3 0 \%}$ & $\$ 802,251$ & $\$ 91,763$ & $\$ 170,178$ & $\$ 1,942$ & $\$ 1,066,134$ \\
\hline $\mathbf{5 0 \%}$ & $\$ 814,494$ & $\$ 102,413$ & $\$ 185,864$ & $\$ 1,917$ & $\$ 1,104,688$ \\
\hline $\mathbf{7 0 \%}$ & $\$ 816,428$ & $\$ 113,063$ & $\$ 201,550$ & $\$ 1,890$ & $\$ 1,132,931$ \\
\hline $\mathbf{9 0 \%}$ & $\$ 818,362$ & $\$ 123,713$ & $\$ 217,235$ & $\$ 1,865$ & $\$ 1,161,175$ \\
\hline
\end{tabular}

Table 2 shows the overall revenue, from the streams we have modelled, for a VLCA practice. The same figures as Table 1 apply here, except for the addition of VLCA funding and the exclusion of Fees-free under 14 s funding.

Table 2: Annual practice income from all funding streams for hypothetical VLCA practices. (Figures in NZ\$)

\begin{tabular}{|llllll|}
\hline & $\begin{array}{l}\text { First level service } \\
\text { Capitation }\end{array}$ & VLCA & CSC & HUHC & Totals \\
\hline $\begin{array}{l}\text { Proportion of high needs } \\
\text { patients }\end{array}$ & & & & & \\
\hline $\mathbf{3 0 \%}$ & $\$ 802,251$ & N/A & $\$ 170,178$ & $\$ 1,942$ & $\$ 974,371$ \\
\hline $\mathbf{5 0 \%}$ & $\$ 814,494$ & $\$ 312,961.18$ & $\$ 185,864$ & $\$ 1,917$ & $\$ 1,315,236$ \\
\hline $\mathbf{7 0 \%}$ & $\$ 816,428$ & $\$ 273,813.14$ & $\$ 201,550$ & $\$ 1,890$ & $\$ 1,293,681$ \\
\hline $\mathbf{9 0 \%}$ & $\$ 818,362$ & $\$ 251,256.54$ & $\$ 217,235$ & $\$ 1,865$ & $\$ 1,288,719$ \\
\hline
\end{tabular}

\section{Discussion}

Based on our five hypothetical practices, the levels of revenue show that capitation funding alone does not account for the concentrations of complexity associated with serving high needs populations in general practices. Our study shows that VLCA practices, who are required to serve at least a $50 \%$ proportion of high needs people, are no more financially advantaged than practices who do not serve these populations. This demonstrates the inequitable funding implications of a formula that uses age and sex as its key demographics to inform need status amongst Māori, Pacific people and people living in areas of high deprivation.

VLCA funding; a resource designed to improve access to care for high needs populations, appears to not account for populational differences in it's formula. Despite the knowledge that high needs populations have different demographic characteristics then non-high needs populations (i.e, high needs groups have a different age distribution which are more skewed towards younger age groups compared to non-high needs groups) the formula use the same demographic information as the first level capitation formula, a funding stream which serves a different population and purpose. For[JC1] example, our hypothetical practices with $90 \%$ high needs people has a lower income from the VLCA stream than that of a practice with $70 \%$ high needs people. If the VLCA formula was successful in its goal to 
support practices serving high levels of high needs patients, we would expect to see funding increase as proportions of high needs patients increase. The VLCA formula is not weighted according to prevalence of illness despite the known importance of weighting as a tool to increase accuracy when harnessing funds for an established priority ${ }^{18}$. A recent comparison of seven countries ${ }^{19}$, observed that their needs to be a viable connection between policy goals and funding formula to deter the persistence of perverse incentives. In this case, that would mean better aligning the equity goals off the Primary Health Care Strategy to the VLCA funding formula.

Although we did not model user copayments, others have done so ${ }^{20}$. They show that the slight increase in funding with the caveat of capped co-payments and other drawbacks associated with serving high needs populations such as higher patient turnover and higher levels of unpaid copayments, means that VLCA practices can stand to be financially burdened by serving elevated levels of high needs people. A 2016 report by the National Hauora Coalition highlighted the higher levels of debt associated with unpaid or uncharged copayment which are more likely to affect practices which serve higher levels of high needs people. ${ }^{21}$ [JC2] Moreover, non VLCA and practices who do not serve high proportions of CSC holders are not constrained by capped copayments and can charge more, making the disparity between practice funding even more pronounced.

\section{Strengths and weaknesses}

Whilst this study covers the main sources of funding for general practice, some are left out. Some[MIL3] , we considered the contribution to net income as negligible and for others the information was not accessible or relevant for inclusivity. Service [MIL4] to Improve Access funding, for example, which accounted for $5 \%$ of total PHO funding in 2019 , was designed to improve access to primary care services. This funding was intended to acknowledge the fact that high needs groups had been shown to have very similar usage rates of primary care services, even though they have worse health status, likely due to significant barriers to accessing care (e.g., from co-payments, lack of transport or caregiving support, inability to get time off work, etc.). This scheme is funded on a case-by-case basis for specific initiatives, with the funding going to PHOs in the first instance rather than practices. Whilst Service to Improve Access funding is targeted specifically for high needs populations, it serves a different purpose and it is difficult to quantify using our modelling approach. The same reasons apply for the exclusion of Care Plus funding, a pool designed at creating unique care plans for people with 2 or more chronic conditions. The income that Care Plus generates for practices only totals $6.8 \%$ of overall income and is limited to $5 \%$ of the population. Care Plus [MIL5] funding goes directly to practices and criteria are localized to each PHO. It is worth mentioning that the HUHC are in the process of being replaced with Care Plus and this may contribute to the low impact of HUHC payments on total practice income. Other funding streams we did not incorporate include rural funding and funds delegated to help practices serving a high proportion of nonresidents. [MIL6]

One strength of this study is the use of up-to-date enrolment data which provided us with an accurate demographic spread. This means our results can be fairly generalisable [MIL7] to the population of Aotearoa New Zealand. However, the hypothetical nature of our models limits the inferences that we can make for real practices. The actual demographic breakdown will differ from one practice to another, and hence so will the revenue earned from capitation funding.

Use of enrolment data was appropriate for our study but does not show the level of unmet need or unenrolled people who are seeking care ${ }^{22}$. Future research could further address high needs populations to assess the number of people with multiple chronic conditions who go on to use greater levels of secondary or tertiary care due to their condition not being appropriately treated at a primary level. 
The finding that a capitation formula which is determined only by age and sex does not account for differences between populations, is supported by the literature ${ }^{23}$. Penno et al state that if demographic-based models are not risk adjusted, they can perpetuate long standing health disparities. The same paper found that Aotearoa New Zealand and Stockholm were the only regions which depended on age and sex as a predictor of need rather than using this in conjunction with disease status. This implies that consideration of chronic disease is a crucial factor when deciding how much funding a population should be allocated. Literature from Canada also support our finding that complexity of cases within the population of a practice has an implication on funding requirements, they report physicians serving low-income patients are often underfunded due to longer consultation time and case complexity ${ }^{13}$. Our findings also grow the body of knowledge that highlight the structural discrimination towards Māori in the health system. 242526 .

\section{Implications}

The implications of this study are that practices may be forced to make a choice between financial stability and serving people who are most in need of care. Thus, the financial incentives built into the Aotearoa New Zealand funding formula may lead to 'cream skimming' and/or 'skimming'. That is, practices may choose to not enrol high needs patients as a result of the capitation funding being insufficient to support working with more complex populations, or they may skimp on care, either to encourage patients to leave and enrol elsewhere or to simply be able to manage with the funding provided. Although we have no direct evidence of this, we do know that enrolment rates for indigenous population groups are lower than for others and have been dropping for some time ${ }^{22}$. Capitation formulas transfer key financial risks from payers to providers; if the primary care provider cannot afford this risk, then the consequences transfer down to patients[JC9] .

Aotearoa New Zealand and Australia are the only OECD countries which recognise indigenous ethnicity as a standalone predictor of health status and incorporate it into national funding formulas (Some countries, such as the Netherlands include ethnicity in their measures of socio-economic status) ${ }^{23}$. This study could be used to inform decisions on formula for other countries such as Canada or the United States who have indigenous populations who suffer poorer health status then non-indigenous populations[JC10] ${ }^{27}{ }^{28}$. [MIL11]

\section{Structural inequity}

Based on the funding available to practices who serve greater levels of high needs patients, there is evidence of structural discrimination in the health sector. Funding formula must recognise differences in needs if they are 1) to be fair, 2) if those with higher needs are to receive the services they require, and 3) if the practices serving a higher needs population are to be financially sustainable. Capitation formula [MIL12] typically do recognise need in terms of age, as older people are more likely to have higher needs, often from having multiple long-term conditions. However, in ANZ, funding formula should take into account that Māori and Pacific populations typically develop longer term conditions at a younger age and are more likely to have multiple conditions. Initiatives including HUHCs and CSC aim to reduce this inequity, but their efficacy is debatable. We have demonstrated that the differences in practice level revenue is negligible in reducing the deficit between those serving low and high proportions of high need patients. Issues such as low level of uptake and inefficiency at capturing the nuance of low income (for example, some eligibility thresholds for single people sit below the minimum wage) mean that the CSC scheme does not always reach its intended population

${ }^{11}$. HUHC have not been evaluated in the literature, but Ministry of Health data shows that the uptake may be far less than eligible population ${ }^{29}$. 


\section{Conclusion}

In conclusion, information from our hypothetical modelling shows the existence of structural discrimination within the capitation funding formula of Aotearoa New Zealand. Use of age as a main determinant for capitation funding perpetuates the longstanding neglect, from the health system, to acknowledging the younger age distribution of high needs populations. Initiatives such as High Use Health Card and Community Service Cards, struggle to achieve this target and do not contribute meaningfully to overall funding. We do not believe that general practices who serve a high proportion of high needs patients are adequately funded to do so.

\section{Declarations}

\section{Ethical Approval and Consent to participate}

Not Applicable

Consent for publication

All authors give consent for the manuscript to be published

\section{Availability of data and materials}

Not Applicable

\section{Competing interests}

The authors declare that there are no competing interests

\section{Funding}

This research was supported by a grant from the Research and Education Committee of the Royal New Zealand College of General Practitioners (2021) and the Health Research Council of New Zealand, grant 18/667.

\section{Authors' contributions}

Mona Jeffreys, Maite Irurzun Lopez, Jacqueline Cumming, Peter Crampton and Kenny Hau contributed to the design of the work.

Jeffreys obtained the funding for the project. Tessa Senior collected the data and performed the analysis. All authors collectively interpreted the data. Tessa Senior drafted the manuscript. All authors critically commented for intellectual content and approved the final version of the manuscript.

\section{Acknowledgements}

We would like to thank Dr Tom Love for his helpful comments on an earlier verion of this manuscript.

\section{References}


1. Health Systems Institutional Characteristics: A Survey of 29 OECD Countries | READ online. oecd-ilibrary.org. Accessed December 16, 2021. https://read.oecd-ilibrary.org/social-issues-migration-health/health-systemsinstitutional-characteristics_5kmfxfq9qbnr-en

2. Smith, Peter C. Formula Funding of Public Services. Published 2007. Accessed November 2, 2021. https://library.oapen.org/viewer/web/viewer.html?file=/bitstream/handle/20.500.12657/24246/1005885.pdf? sequence=1\&isAllowed $=y$

3. Penno E, Gauld R, Audas R. How are population-based funding formulae for healthcare composed? A comparative analysis of seven models. BMC Health Serv Res. 2013;13(1). doi:10.1186/1472-6963-13-470

4. The Primary Health Care Strategy. Ministry of Health NZ. Accessed October 8, 2021. https://www.health.govt.nz/publication/primary-health-care-strategy

5. PHO-Services-Agreement-Version-6.3-1-July-2021.pdf. Accessed November 2, 2021. https://tas.health.nz/assets/Primary-Care/PHO-Services-Agreement-Version-6.3-1-July-2021.pdf

6. ttp_c12.pdf. Accessed November 30, 2021. https://www.moh.govt.nz/NoteBook/nbbooks.nsf/0/B5DEDA9A12DACE3B4C25677D00720599/\$file/ttp_c12.pdf

7. Ministry of Health. Data supplied by Ministry of Health. Published online 2021.

8. About primary health organisations. Ministry of Health NZ. Accessed December 16, 2021. https://www.health.govt.nz/our-work/primary-health-care/about-primary-health-organisations

9. Downs A Fulbright New Zealand, lan Axford (N.Z.) Fellowships in Public Policy. From Theory to Practice: The Promise of Primary Care in New Zealand.; 2017. Accessed October 8, 2021. http://www.fulbright.org.nz/wpcontent/uploads/2017/09/DOWNS-From-Theory-to-Practice-The-Promise-of-Primary-Care-in-New-Zealand-.pdf

10. Atkinson J, Salmond C, Crampton P. NZDep2018 Index of Deprivation. Published online 2020:65.

11. Crampton P. The ongoing evolution of capitation funding for primary care: the December $2018 \mathrm{PHO}$ capitation funding changes for Community Services Card holders. N Z Med J Online. 2019;132(1498):69-78.

12. Wai 2575, A062.pdf. Accessed November 30, 2021.

https://forms.justice.govt.nz/search/Documents/WT/wt_DOC_142252871/Wai\%202575\%2C\%20A062.pdf

13. Shin S, Schumacher C, Feess E. Do Capitation-based Reimbursement Systems Underfund Tertiary Healthcare Providers? Evidence from New Zealand. Health Econ. 2017;26(12):e81-e102. doi:10.1002/hec.3478

14. bpj13_cardio_pages_15-19.pdf. Accessed October 8, 2021. https://bpac.org.nz/bpj/2008/may/docs/bpj13_cardio_pages_15-19.pdf

15. Hau, Kenny, Cumming, Jacqueline, Irurzun Lopez, Maite, Jeffreys, Mona, Crampton, Peter P. Submitted manuscript: Concentrations of compleity in primary care: analysis of New Zealand Health survery data.

16. Flynn M, Carne S. Māori Housing Trends 2010. :96.

17. New Zealand Health Survey. Ministry of Health NZ. Accessed November 19, 2021. https://www.health.govt.nz/nzhealth-statistics/national-collections-and-surveys/surveys/new-zealand-health-survey

18. Miller HD. The Building Blocks of Successful Payment Reform: 2015;(3):85.

19. Johnston BM, Burke S, Kavanagh PM, O'Sullivan C, Thomas S, Parker S. Moving beyond formulae: a review of international population-based resource allocation policy and implications for Ireland in an era of healthcare reform. Published online November 23, 2021. doi:10.12688/hrbopenres.13453.1

20. Young M, Comendant C. Methodology for Estimating the Underfunding of Māori Primary Health Care. :66.

21. Woodhams N, National Hauora Coalition. The Sustainability of Very High Needs Primary Care Practices in a Capitated Environment:; 2016. Accessed December 2, 2021. http://natlib- 
primo.hosted.exlibrisgroup.com/NLNZ:NLNZ:NLNZ_ALMA11272001230002836

22. Irurzun-Lopez M, Jeffreys M, Cumming J. The enrolment gap: who is not enrolling with primary health organizations in Aotearoa New Zealand and what are the implications? An exploration of 2015-2019 administrative data. Int J Equity Health. 2021;20(1):93. doi:10.1186/s12939-021-01423-4

23. How are population-based funding formulae for healthcare composed? A comparative analysis of seven models Document - Gale Academic OneFile. Accessed October 8, 2021. https://go-gale-com.helicon.vuw.ac.nz/ps/i.do? $p=A O N E \& u=v u w \& i d=G A L E \% 7 C A 534637149 \& v=2.1 \& i t=r$

24. Langton J, Crampton P. Capitation funding of primary health organisations in New Zealand: are enrolled populations being funded according to need? N Z Med J Online. 2008;121(1272):47-58.

25. Came H, Baker M, McCreanor T. Addressing Structural Racism Through Constitutional Transformation and Decolonization: Insights for the New Zealand Health Sector. J Bioethical Inq. 2021;18(1):59-70. doi:10.1007/s11673-020-10077-w

26. Chin $\mathrm{MH}$, King PT, Jones RG, et al. Lessons for achieving health equity comparing Aotearoa/New Zealand and the United States. Health Policy. 2018;122(8):837-853. doi:10.1016/j.healthpol.2018.05.001

27. Reducing health inequalities: A challenge for our times | National Collaborating Centre for Determinants of Health. Accessed December 15, 2021. https://nccdh.ca/resources/entry/reducing-health-inequalities-a-challenge-for-ourtimes

28. Integrated Care with Indigenous Populations: Considering the Role of Health Care Systems in Health Disparities ProQuest. Accessed December 15, 2021. https://www.proquest.com/docview/2184239853? parentSessionld=IhBIWzmBQSzO\%2BeZSpOheMsM8mxqsLos9\%2B29\%2F\%2BmFzt4c\%3D\&pqorigsite $=$ primo\&accountid $=14782$

29. Enrolment in a primary health organisation. Ministry of Health NZ. Accessed November 2, 2021. https://www.health.govt.nz/our-work/primary-health-care/about-primary-health-organisations/enrolment-primaryhealth-organisation

\section{Figures}

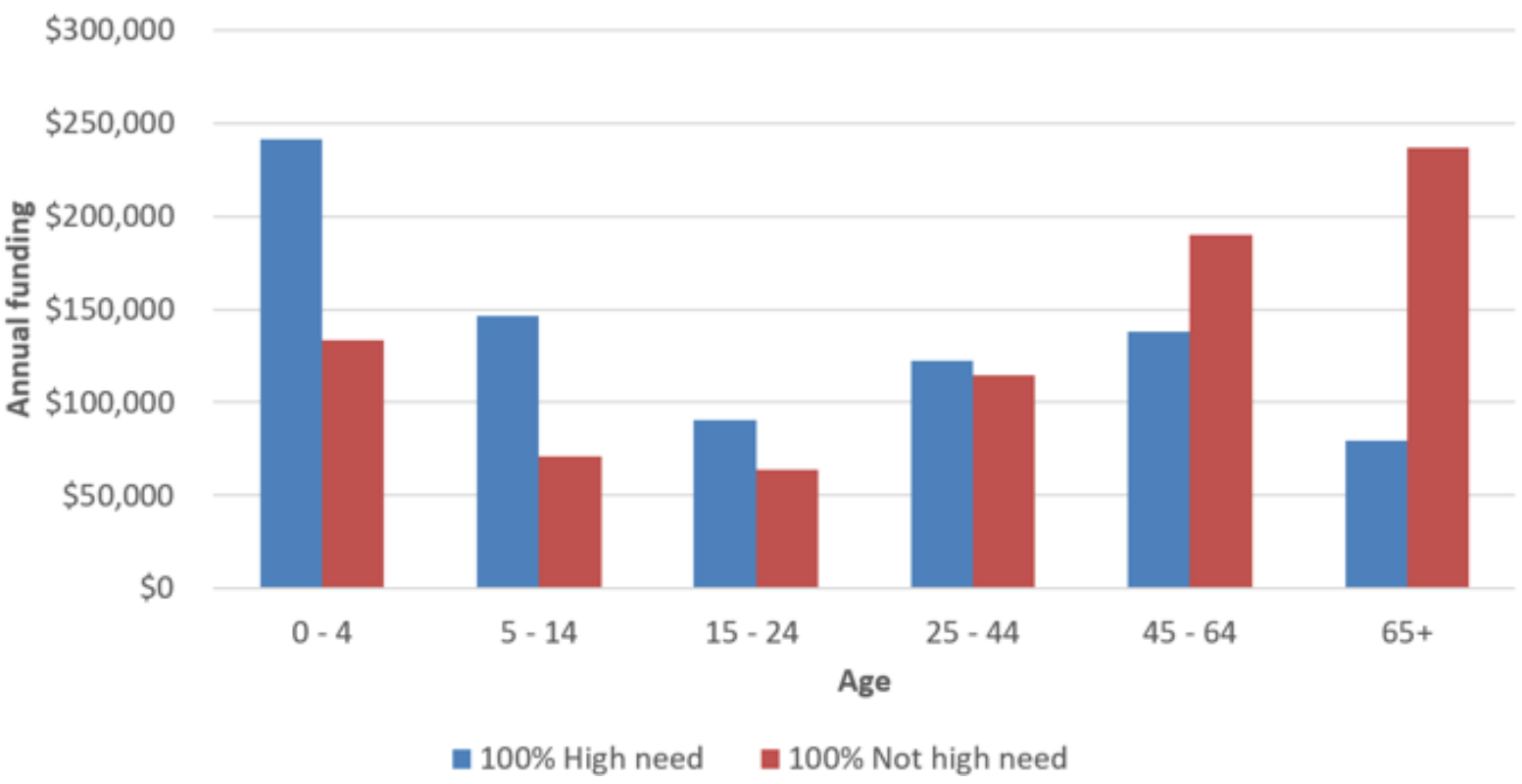

Figure 1

Page $11 / 12$ 
Hypothetical First level service capitation funding totals for $100 \%$ high need and $100 \%$ not high need practices . (not including HUHC payments) (Figures in NZ\$)

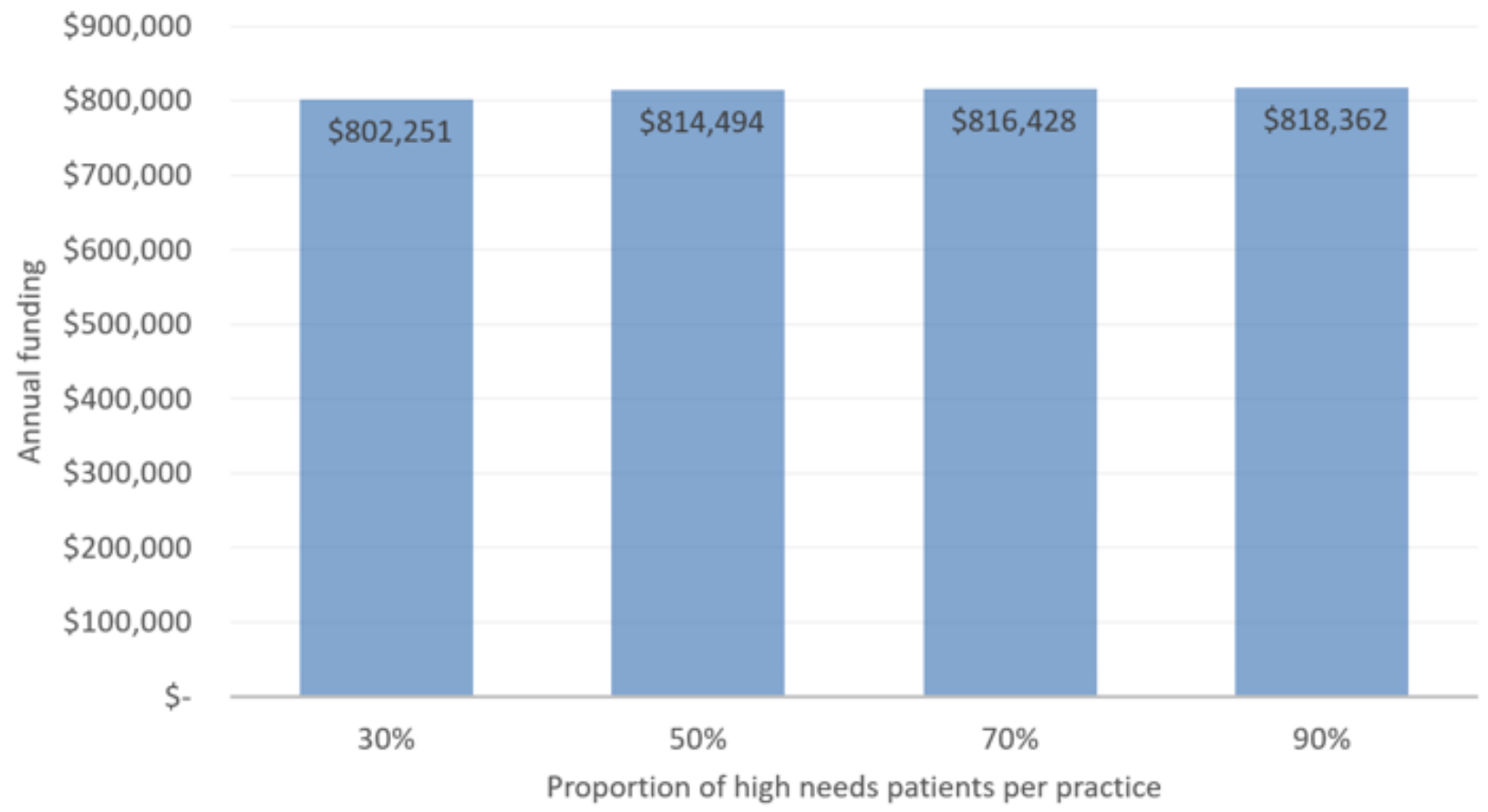

\section{Figure 2}

First level services capitation funding totals for each hypothetical practice. (Figures in NZ\$)

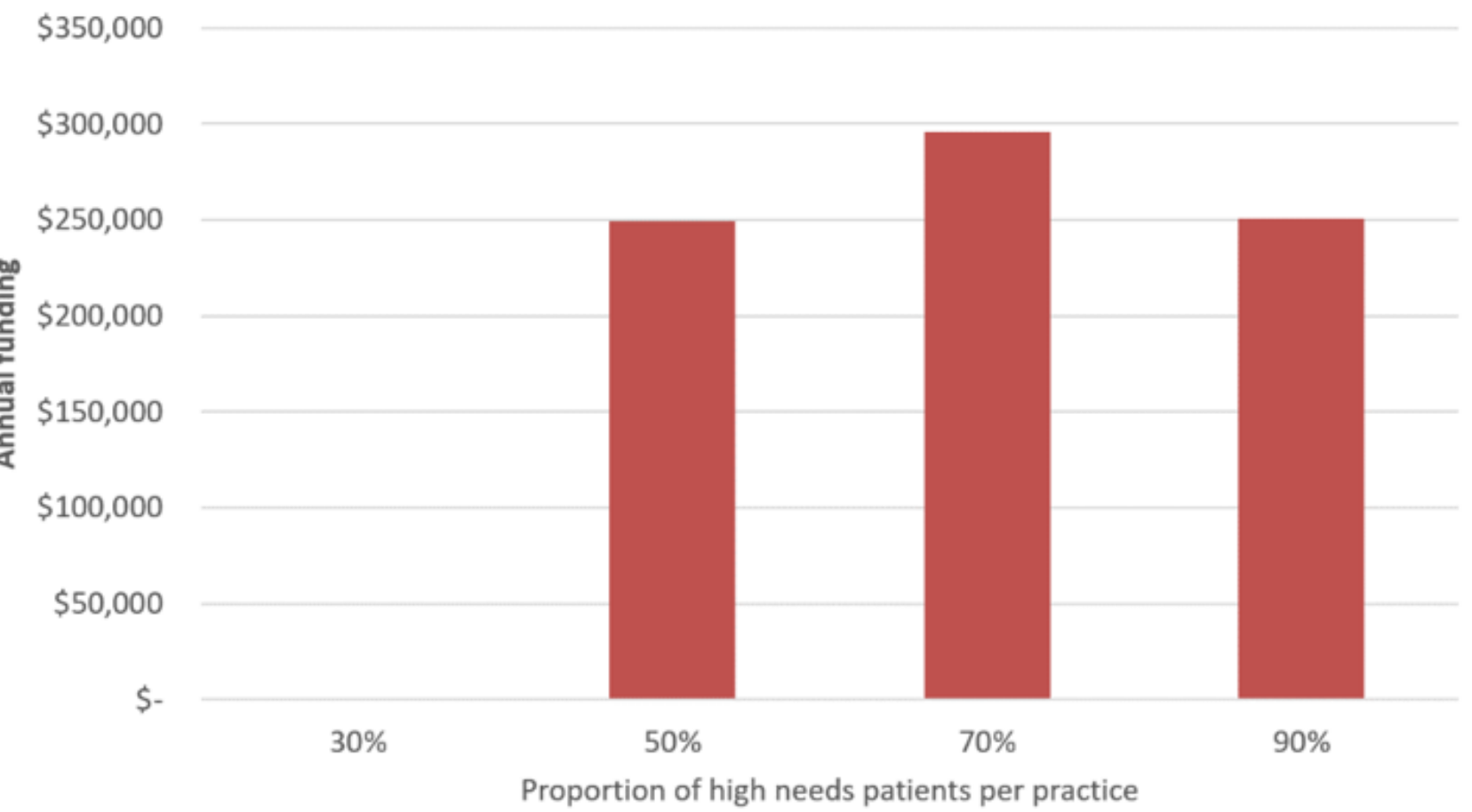

\section{Figure 3}

VLCA funding for each hypothetical practice. (Figures in NZ\$) 